\title{
A Study on the Knowledge, Attitude and Practice about Contraception in Postpartum Women of North India
}

\author{
Dr Jayati Nath ${ }^{1}$, Dr Farzana Islam ${ }^{2}$ \\ ${ }^{1}$ Associate Professor. Obstetrics \& Gynaecology, MMIMSR, Ambala, India \\ ${ }^{2}$ Assistant Professor, Community Medicine, Hamdard Institute of Medical Science \& Research (HIMSR), New Delhi, India
}

\begin{abstract}
Aim of the study: This study was undertaken to evaluate the knowledge and attitude about contraception in postpartum women in a tertiary care medical college in North India. Materials \& Methods: We conducted a cross-sectional study in the department of Obstetrics \& Gynaecology of Maharishi Markandeshwar Institute of Medical Science \& Research (MMIMSR), Ambala ,Haryana between January 2014 and January 2015 . Five hundred (500) postpartum and post-abortal women were randomly selected, subjected to our detailed, pre-formatted questionnaire and were questioned and counselled about various methods of contraception. Their knowledge and awareness about emergency contraception pill and MTPill were also noted. Results \& Observations: In our study we observed that only $72 \%$ of the ladies had heard about various methods of contraception. Most patients knew about IUCD \& OCPs. Most patients came to know about contraception from television \& doctors and other healthcare givers. After proper counselling, $95 \%$ patients opted for IUCDs, barrier method ( male condom) and injection DepoProvera. Only $25 \%$ patients knew about emergency contraceptive pill and $36 \%$ patients had knowledge about MTPill. Conclusion: There is a great lacuna in the awareness of contraception, emergency contraception and medical abortion in the women under study. Regular detailed and proper counselling is a must to all postpartum and post-abortal women. Women should be given the cafeteria approach for contraception by providing detailed and comprehensive information about the various methods available and they should be given a choice to choose the method of contraception best suited to their needs, which will help improve the general health of the women and their children.
\end{abstract}

Keywords: contraception, emergency contraception,knowledge, MTPill,post-abortal women, post-partum women

Abbreviations: IUCD - intra uterine contraceptive device

OCP- oral contraceptive pill

MTPill - medical termination of pregnancy pill

\section{Introduction}

A woman's reproductive right - including the right to decide the number, timing and spacing of her children - is absolutely fundamental to women empowerment and equality. Postpartum and post-abortal periods are very crucial for a woman as for many patients who belong to the rural areas, this may be the only time she comes in contact with a health personnel .Hence counselling done at this period is very crucial and effective too. The postpartum period is an important time to initiate contraception because women are accessing the healthcare system and might have increased motivation to avoid another pregnancy. Ovulation can occur as early as 25 days postpartum among nonbreastfeeding women, underscoring the importance of initiating contraception in the early postpartum period (1) .The dynamics of contraception use among women in the extended postpartum period ie one year period after the birth of the child, is of much more interest at the family planning programme level, since delay of use until the return of menstruation might subject women to the risk of unwanted pregnancy. An increase in contraceptive use during the postpartum period substantially reduces the rates of maternal and infant mortality by preventing unplanned and unwanted pregnancies and spacing new pregnancies to at least three years after the previous birth (2). As a matter of fact, the largest population of women with an unmet need for contraception is found among those in their first year after childbirth (3) . Mortality risks are elevated for both the previous child and for the newborn infant if birth intervals are shorter than expected (4). In India the higher proportion of unplanned pregnancies might be due to shorter birth intervals. In this context, postpartum period becomes more crucial for initiating contraception to space births in a healthy fashion (5). In order to reduce the risk of adverse maternal, perinatal and infant outcomes, WHO (2006), recommended that the interval between a livebirth and an attempt to the next pregnancy should be 24 months (6). Short birth intervals $(<24$ months) also have a potential effect on the increased risk of maternal death and complications of pregnancies (7). According to National Family Health Survey 2005-2006, U.P. , India , the unmet need for family planning in currently married women of reproductive age group is $21.2 \%$ (5). Among the common reasons for the above, are inconvenient, unsatisfactory services, lack of information, fears about contraception side effects and opposition from husbands, relatives or others (9) . Embracing the principle of Family Planning and adoption of birth control measures reduces unintended pregnancies and unsafe abortions, averts maternal and neonatal deaths and leads to a decline in the number of women facing complications due to unsafe pregnancies $(7,8,9)$. The process of selection of an appropriate contraception is a major concern in postpartum period. 


\section{International Journal of Science and Research (IJSR) \\ ISSN (Online): 2319-7064}

Index Copernicus Value (2013): 6.14 | Impact Factor (2014): 5.611

\section{Aims and Objectives}

This cross -sectional study was undertaken to assess the attitude and knowledge about contraception in the postpartum and post-abortal women in a tertiary care medical college of north India- Teerthanker Mahaveer Medical College \& Research Centre (TMMCRC).

\section{Materials and Methods}

A cross-sectional study was conducted in the department of Obstetrics \& Gynaecology of Maharishi Markandeshwar Institute of Medical Science and Research (MMIMSR), Ambala, Haryana from January 2014 to January 2015. A total of 500 post-partum \& post-abortal women attending the OPD, IPD, Emergency services were randomly enrolled in the study. The patients were given a pre-tested, prestructured questionnaire and their answers noted and analyzed. Ethical requirement of informed consent and confidentiality were ensured before the onset of the study.

The patients enrolled in the study were thoroughly interviewed on their knowledge \& awareness about contraception \& the various methods available thereof. They were counseled about various contraceptive methods available and were allowed to choose a method of their choice for contraception. They were also questioned about their awareness of Emergency Contraception Pill \& Medical Termination of Pregnancy Pill (MTPill). Data thus collected were tabulated, sorted out and analyzed by entering in Microsoft excel and SPSS version -15 was used for the statistical analysis.

\section{Results \& Observations}

The various results obtained from our study were tabulated and later on analysed.

Table 1: Socio-demographic profile of the patients

\begin{tabular}{|c|c|c|c|}
\hline A & Maternal Age (yrs) & Number & Percentage (\%) \\
\hline & $15-24$ & 165 & 33 \\
\hline & $25-34$ & 290 & 58 \\
\hline & $35-45$ & 45 & 9 \\
\hline B & Parity & Number & Percentage (\%) \\
\hline & 2 & 201 & 40.2 \\
\hline & $>2$ & 94 & 18.8 \\
\hline
\end{tabular}

Table 2: Socio-economic status

\begin{tabular}{|c|c|c|}
\hline Modified KUPPUSWAMY Score & Number & Percentage \\
\hline Upper (I) & 29 & 5.8 \\
\hline Upper Middle (II) & 76 & 15.2 \\
\hline Middle/Lower Middle(III) & 57 & 11.4 \\
\hline Lower/Lower Middle(IV ) & 200 & 40.0 \\
\hline Lower (V) & 138 & 27.6 \\
\hline
\end{tabular}

$47 \%$ patients belonged to the rural areas whereas the rest 53 $\%$ hailed from the urban areas.

Out of the total 500 number of women enrolled in the study, only 360 had knowledge about contraception (72\%), and the rest $140(28 \%)$ had no idea about the same.
Table 3: Knowledge based on parity

\begin{tabular}{|c|c|c|c|}
\hline Obstetric History & Aware & Unaware & Number \\
\hline Para 1 & 95 & 40 & 135 \\
\hline Multipara & 265 & 100 & 365 \\
\hline
\end{tabular}

Table 4: Knowledge based on Socio-economic status

\begin{tabular}{|c|c|c|c|}
\hline Social Class & Aware & Unaware & Total Number \\
\hline Upper (I) & 42 & 1 & 43 \\
\hline Upper Middle (II) & 59 & 14 & 73 \\
\hline Middle/Lower middle(III) & 150 & 132 & 282 \\
\hline Lower/ Upper lower(IV) & 19 & 73 & 92 \\
\hline Lower (V) & 1 & 9 & 10 \\
\hline TOTAL & 360 & 140 & 500 \\
\hline
\end{tabular}

Table 5: Knowledge based on Contraception

\begin{tabular}{|c|c|c|c|}
\hline Occupation & Aware & Unaware & Total \\
\hline Housewife & 236 & 134 & 370 \\
\hline Skilled personnel & 89 & 6 & 95 \\
\hline Professional & 35 & 0 & 35 \\
\hline TOTAL & 360 & 140 & 500 \\
\hline
\end{tabular}

Table 6: Source of knowledge

\begin{tabular}{|c|c|c|}
\hline Source Of Knowledge & Number & Percentage (\%) \\
\hline Family & 100 & 20.0 \\
\hline Doctor & 125 & 25.0 \\
\hline Asha Worker & 45 & 9.0 \\
\hline Books \& news & 50 & 10.0 \\
\hline Television & 180 & 36.0 \\
\hline
\end{tabular}

Table 7: Knowledge about different methods of contraception (among those aware about contraception)

\begin{tabular}{|c|c|c|}
\hline Method PF Contraception & Number & $\begin{array}{c}\text { Percentage } \\
(\%)\end{array}$ \\
\hline IUCD & 298 & 82.77 \\
\hline Barrier Method & 275 & 76.38 \\
\hline OCP (POP) & 153 & 42.50 \\
\hline DMPA Injection Depo Provera & 138 & 38.33 \\
\hline Lactational Amenorrhoea Method (LAM) & 35 & 9.72 \\
\hline Safe Method & 10 & 2.77 \\
\hline TOTAL & 360 & \\
\hline
\end{tabular}

After thorough counselling on post-partum contraception \& giving them an informed choice, $95 \%$ patients ie 345 out of the total 500 women wanted contraception. The choices preferred were as tabulated below in Table 8 .

Table 8: Methods of Contraception chosen after counselling

\begin{tabular}{|c|c|c|}
\hline Method of Contraception & Number & $\begin{array}{c}\text { Percentage } \\
(\%)\end{array}$ \\
\hline IUCD & 186 & 37.2 \\
\hline Barrier Method & 87 & 17.4 \\
\hline OCP (POP) & 52 & 10.4 \\
\hline DMPA Injection Depo Provera & 138 & 27.6 \\
\hline Lactational Amenorrhoea Method (LAM) & 22 & 4.4 \\
\hline Safe Method & 15 & 3.0 \\
\hline No Method & 25 & 5.0 \\
\hline
\end{tabular}

The two key factors which influenced the knowledge of contraception were education level \& occupation of the woman and the socio-economic status measured by the Modified Kuppuswamy Score.

The various myths and beliefs that these women had regarding contraception were as follows: 


\section{International Journal of Science and Research (IJSR)}

ISSN (Online): 2319-7064

Index Copernicus Value (2013): 6.14 | Impact Factor (2014): 5.611

a) $\underline{\mathrm{Cu}-\mathrm{T}}$

- Polymenorrhagia : $27 \%$ patients

- Infection : $9 \%$

- Weakness : $5 \%$

- White discharge PV : $10 \%$

- Lower abdominal pain : $15 \%$

- Cancer : $4 \%$

b) $\underline{\mathrm{OCP}}$

- Polymenorrhagia : $13 \%$

- Infertility : $2 \%$

- Weight gain : $28 \%$

- Cancer : $5 \%$

c) Barrier Method

d) Skin infections : $9 \%$

- Injection DMPA

- Polymenorrhagia : $11 \%$

- Infertility : $19 \%$

- Cancer : $12 \%$

Table 9: Knowledge about Emergency Contraception Pill

\begin{tabular}{|c|c|c|c|}
\hline Knowledge & $\begin{array}{c}\text { Emergency } \\
\text { Contraceptive } \\
\text { Pill }\end{array}$ & Total & \\
\hline & NO & YES & \\
\hline NO & 130 & 10 & 140 \\
\hline Count \% within knowledge & $92.8 \%$ & $7.2 \%$ & $100.00 \%$ \\
\hline YES & 295 & 65 & 360 \\
\hline Count \% within knowledge & $81.9 \%$ & $18.1 \%$ & $100.00 \%$ \\
\hline TOTAL & 425 & 75 & 500 \\
\hline Count \% within knowledge & $85.0 \%$ & $15.0 \%$ & $100.00 \%$ \\
\hline
\end{tabular}

Table 10: Knowledge about MTPill

\begin{tabular}{|c|c|c|c|}
\hline & MTPill & & Total \\
\hline & NO & YES & \\
\hline NO & 120 & 20 & 140 \\
\hline Count \% within knowledge & $86.0 \%$ & $14.0 \%$ & $100.0 \%$ \\
\hline YES & 240 & 120 & 360 \\
\hline Count \% within knowledge & $66.7 \%$ & $33.3 \%$ & $100.0 \%$ \\
\hline TOTAL & 325 & 175 & 500 \\
\hline Count \% within knowledge & $65.0 \%$ & $35.0 \%$ & $100.0 \%$ \\
\hline
\end{tabular}

MTPill was known to only $35 \%$ patients (175 out of the total 500 women ) \& Emergency Contraceptive Pill was known to $15 \%$ patients ( 75 out of the total 500 ).

\section{Discussion}

Very few studies have been conducted on awareness \& knowledge of contraception in post-partum or post-abortal women. Out of the total 500 women enrolled in our study, only $72 \%(360 / 500)$ had heard about various methods of contraception. IUCD was known to $82.77 \%$, OCP to 42.5 $\%$, Barrier method (Male condom ) to $76.38 \%$, lactational amenorrhoea method was known to $9.72 \%$, Inj Depo Provera (DMPA) to $38.83 \% 72.77 \%$ were aware of the Safe Method. The main source of information was television \& doctors and other healthcare personnel . After receiving post-partum contraception counselling during our study, as many as $95 \%$ women were willing to use contraception. They opted for the choice of contraception as - $37.2 \%$ opted for IUCD , $17.4 \%$ for barrier method (Male condom), DepoProvera injection was chosen by $27.6 \%$, Progesterone Only OCP by $10.4 \%$, lactational amenorrhoea method was chosen by $4.4 \%$, Safe method was chosen by 3 $\%$ of the patients. However, $5 \%$ patients did not go for any contraceptive method but opted for abstinence for the same purpose. Emergency contraceptive Pill was known to only $15 \%$ of the patients $(75 / 500)$. Only $35 \%$ knew about MTPill (175/500). In a similar study by Syed Esam Mahmood et al, the prevalance of post-partum contraception was $13.8 \%$ in the rural females of Bareilly district of U.P. (11) . Goel et al (2010) in another study reported $28.0 \%$ (10) .A higher post-partum contraception prevalence of 41.0 $\%$ has also been reported from population council study (12). Around $20.0 \%$ of post-partum contraception has been reported by NFHS-3 (2005-2006) for rural U.P. (1).

Kiran G. et al in their study on contraception use among married women in a slum in Mumbai stated $87.7 \%$ of women were aware of at least one method of contraception, $68.4 \%$ women were using a contraception at the time of study, $87.7 \%$ were aware of OCP \& Cu-T , followed by female sterilization $(80.4 \%)$, \& condoms ( $77.5 \%)(13)$. Very low level of awareness was noted by several other studies regarding emergency contraception $(16,17,18,19)$.

In our study, it was evident that the key factors which influenced the knowledge of contraception were education and occupation of the woman \& socio-economic status measured by the Modified Kuppuswamy Score. Similarly, significant association between contraception acceptance \& type of family, socio-economic status \& age at marriage were observed in a study among women of reproductive age group in rural Maharashtra (14)

Other Indian studies have also reported similar facts (14.15). It was observed that contraception use was significantly higher (19.1\%) among females who were delivered at a hospital or health centre as compared to those delivered at home $(8.3 \%)$. This can be attributed to the antenatal and post-natal family planning advice given to the patients delivered at a hospital or health centre.

In a large study conducted in Mexico (16), it was found that women who received family planning advice during postnatal care were more likely to use a contraceptive than those who did not receive such advice. Strong association between maternal health care \& family planning practice has been established in many previous studies $(17,18,19)$.

\section{Conclusion}

It is clearly evident that there is a great lack of awareness and knowledge of contraception in post-natal and postabortal women. Therefore, regular and comprehensive counselling is a must to all pregnant women from every health centre in a village to super-specialty centres in citiesthat is all levels of health care delivery system . proper \& correct information should be provided about various methods of contraception \& patients should be able to choose a method of their choice . There is lack of awareness of Emergency Contraception \& MTPill .

\section{Volume 4 Issue 12, December 2015}




\section{International Journal of Science and Research (IJSR) \\ ISSN (Online): 2319-7064}

Index Copernicus Value (2013): 6.14 | Impact Factor (2014): 5.611

The major limitation of our study was that only a group of patients who seeked health care in a tertiary care centre were interviewed and the results analyzed. Hence, the findings in this study cannot be generalized to the whole state or to the country as a whole. Our study reveals that education level, occupation and socio-economic status are the major limiting factors in accepting Family Planning methods. There is, thus, a great need for proper promotion of spacing methods by policy makers $\&$ field workers $\&$ motivation of couples to accept them.

Women who have recently had a pregnancy event - birth or abortion- need extra attention from family planning and reproductive health programmes if they are to reduce their number of unwanted births \& abortions and to lengthen subsequent birth intervals . To attain these goals, post-natal visits , delivery services \& subsequent health system contacts are promosing avenues which when fully utilized will help us reach post-partum women with an unmet need for and a derire to use family planning services (19) .

It is clear that while it is essential to device programmes to spread awareness among women to use contraception to limit births, it is also imperative to effectively device and implement post-partum family planning programmes in India by integrating them with maternal \& child health services, which will then have a broader cultural acceptance - In addition, women who receive counselling during hospital stay for delivery are more likely to use contraception in post-partum period. Thus, there is need to observe more closely the role of family planning policies and health care providers in effectively generating motivation and knowledge among Indian women to use contraception in post-partum period. Such an approach will break all the myths and wrong beliefs and notions among the general population regarding contraception and various devices that are available and help improve the general health of the women and their children .It is also essential to target the poor and less educated women for the success of post-partum family planning programmes in India .

\section{Conflict of Interest}

None

\section{Ethical Approval}

The study was approved by the institutional ethical committee .

\section{References}

[1] Laurie et al , CDC updates guidelines for postpartum contraceptive use. Medscape, 2011.

[2] $\mathrm{R}$.Vernon . Meeting the family planning needs of postpartum women. Stud Family Planning, 2009 ; 40 (3) : 235-45.

[3] John A Rose et al, Contraceptive use, intention to use and unmet need during the extended postpartum period. Int Family Planning Persp, 2001 ; 27(1): 20-27.
[4] Hobcraft J et al, Demographic and health surveys , Int health Rationale for Family Planning , $1^{\text {st }}$ Ed , New York :United Nations ; 1994: 112.

[5] International Institute for Population Sciences (IIPS) . The $3^{\text {rd }}$ national family health survey (NFHS-3), India, 2005-2006 . Int Insti Sci Mumbai , 2007;2 : 1-168.

[6] World Health Organisation, Report of a WHO technical consultation on birth spacing, In :WHO, eds, WHO report, Geneva : WHO ; 2006:1-37.

[7] Maternal morbidity and mortality associated with interpregnancy interval , Br med j, 2009 , 321 : 12551259.

[8] Effects of birth intervals on infant and under-five mortality rates, Int J of Gyn Obst . 2005 : 89; 7-24.

[9] Husain Zakir et al , Population report : Series J 1997 ; Jun ; 43:3-9.

[10] Goel et al, Increasing postpartum contraception in $\mathrm{U} P$. J Family Welfare . 2010; $56:$ 57-64.

[11] Syed Esam Mahmood et al , Post-partum contraceptive use in rural Bareilly. Indian J of Comm Health . 2011 ;July-Dec, 23 ;(2); 56-57.

[12] International Instt of population Sc , Mumbai , National Family Health Survey, $2007 ; 2: 1-168$.

[13] Kiran G et al , Study of contraceptive use among married women in a slum in Mumbai . Nat $\mathrm{J}$ of Comm Med. 2012, Jan-Mar, 3:40-43.

[14] Murarkar S K et al, Epidemiological correlates of contraceptive use in married women of reproductive age group in rural India . Nat J of Comm Med . 2011, 2 : (1); 78-81.

[15] Chankapa Y D et al, Socio-demographic variables of contraceptive practice in Sikkim, J Pharma Bioall Sci 2011, 3 (3): 368-374.

[16] Barber et al Family Planning and postartum contraception in low-income women in Mexico . Int Fam Planning Persp. 2007 ; 33(1) :6-12.

[17] Chopra et al . Knowledge, attitude and practice of contraception use in urban population of North India , Arch Gynecol Obstet .2010, 281: 273-277.

[18] Tripathi R et al . Emergency contraception in North India , Ind J of Obstet Gynecol Res , 2003 Jun ;29(3):142-146.

\section{Author Profile}

Dr Jayati Nath is Associate Professor in department of OBSTETRICS \& GYNAECOLOGY, Maharishi Markandeshwar Institute of Medical Science and Research, Ambala, Haryana 133207, India 